\title{
Role of dislocations in formation of ohmic contacts to heavily doped $n$-Si
}

\author{
A.E. Belyaev' ${ }^{1}$, V.A. Pilipenko ${ }^{2}$, V.M. Anischik ${ }^{3}$, T.V. Petlitskaya ${ }^{2}$, A.V. Sachenko ${ }^{1}$, \\ V.P. Klad'ko ${ }^{1}$, R.V. Konakova ${ }^{1}$, N.S. Boltovets ${ }^{4}$, T.V. Korostinskaya ${ }^{4}$, \\ L.M. Kapitanchuk ${ }^{5}$, Ya.Ya. Kudryk ${ }^{1}$, A.O. Vinogradov ${ }^{1}$, V.N. Sheremet ${ }^{1}$ \\ ${ }^{I}$ V. Lashkaryov Institute of Semiconductor Physics, NAS of Ukraine, 03028 Kyiv, Ukraine \\ Phone: 38(044) 525-61-82; fax: 38(044) 525-83-42; e-mail: konakova@isp.kiev.ua \\ ${ }^{2}$ State centre "Belmicroanaliz", subsidiary of $R \& D$ Centre "Belmicrosystems", Open Joint Stock Company \\ "Integral”, 220108 Minsk, Belarus \\ ${ }^{3}$ Belarusian State University, 220030 Minsk, Belarus \\ ${ }^{4}$ State Enterprise Research Institute “Orion”, 03057 Kyiv, Ukraine \\ ${ }^{5}$ Paton Institute of Electric Welding, NAS of Ukraine, 03068 Kyiv, Ukraine
}

\begin{abstract}
We present experimental results concerning a high density of structural defects (in particular, dislocations) in the near-contact region of heavily doped $n$-silicon. They appear in the course of firing $\mathrm{Au}-\mathrm{Pd}-\mathrm{Ti}-\mathrm{Pd}-n^{+}-\mathrm{Si}$ ohmic contact at $450{ }^{\circ} \mathrm{C}$ for $10 \mathrm{~min}$ in a vacuum of $\sim 10^{-4} \mathrm{~Pa}$. These defects lead to appearance of metal shunts that determine the current flow mechanism in these ohmic contacts. The calculated and experimental temperature dependences of contact resistivity, $\rho_{c}(T)$, are in good agreement. It is shown that $\rho_{c}$ increases with temperature. This is characteristic of a model of ohmic contacts with a high dislocation density in the near-contact region of semiconductor.
\end{abstract}

Keywords: contact resistivity, ohmic contact, dislocation density, metal shunts.

Manuscript received 29.01.13; revised version received 25.02.13; accepted for publication 19.03.13; published online 25.06.13.

\section{Introduction}

The effect of dislocations on electrophysical parameters of semiconductor materials, discrete devices and integrated circuits is known and well studied [1-12]. The dislocations produced in the course of $p-n$ junction formation, as well as initial growth dislocations, increase the reverse current and induce a nonuniform microplasma breakdown. They reduce the lifetime of minority charge carriers in the active area of device structures as well as lead to other undesirable effects. The dislocation mechanisms of operating parameters degradation were found for the devices operating in the forward branch of the $I-V$ curve (light-emitting diodes, laser diodes, Gunn diodes) and in the reverse branch of the $I-V$ curve (IMPATT diodes, avalanche transistors, high-power rectifiers). The III-N heterostructures grown on foreign substrates are most vulnerable. The dislocation density in them varies within the range of $10^{8}$ to $10^{10} \mathrm{~cm}^{-2}$, depending on a substrate type and growth technique $[6,7]$.

At the same time, there exists a rather well grounded opinion that the presence of some amount of dislocations in the semiconductor active layer is necessary. In this case, at relatively high-temperature manufacturing operations (that are characteristic, e.g., of the technology of silicon or gallium arsenide devices), dislocations can serve as intrinsic gettering centers. They are beneficial for cleaning semiconductor materials and improvement of electrical characteristics [ 8-12].

However, the role of dislocations in formation of such an integral part of semiconductor devices as ohmic contacts has remained relatively unexplored so far. It should be noted, however, that some researchers implicitly indicated the role of structural defects (in particular, dislocations) in fabrication of ohmic contacts 
as early as in the sixties and seventies of the last century [13-16]. To illustrate, ohmic contacts to Si were formed on lapped surface with many structural defects (of a rather high concentration) serving, in particular, as recombination centers. The advantage of the contacts on lapped surface is their high adhesion. The structural factor plays its role in alloyed ohmic contacts, too.

A near-contact region of semiconductor appears owing to alloying contact material with semiconductor, which is followed by relaxation of intrinsic stresses. They appear because the alloy components and semiconductor have different lattice parameters and coefficients of thermal expansion $\alpha$. As a result, the near-contact region of semiconductor has many structural defects, and among them - dislocations. It was intuitively believed that the predominant mechanism of current flow in these contacts is the recombination mechanism that ensures a low contact resistance. However, quantitative agreement between experimental data and calculated dependences has not been achieved. Even for silicon devices, temperature dependences of contact resistivity, $\rho_{c}(T)$, still remain unexplored in a wide temperature range, despite the fact that silicon properties have been studied most comprehensively (as compared with other semiconductor materials), and the manufacturing technology for silicon devices is intensely developed.

Some works in that area have recently appeared in the context of developing the elemental base for extremal electronics. The demand for these works arose from the necessity to estimate contact resistivity $\rho_{c}$ at operating temperatures much above room temperature as well as at maximal temperature appearing under extreme conditions of electronic devices operation. It was found then that $\rho_{c}$ grows with temperature in the hightemperature region [17-25]. This result could not be explained within the existing models. The explanation by Gol'dberg et al. [17-20, 23] referred only to a version of alloyed ohmic contact, under assumption that the current flows via metal shunts associated with dislocations. In that case, contact resistivity $\rho_{c}$ should increase linearly with temperature due to metallic conduction via shunts.

Taking into account the model by Gol'dberg et al., a more general explanation for the experimental dependences $\rho_{c}(T)$ was proposed in [24-28]. Using ohmic contacts to lapped $\mathrm{Si}$ as an example, it was shown that the calculated shunt density was close to the dislocation density $\left(\sim 10^{7} \mathrm{~cm}^{-2}\right)$ determined from the etch pits on the initial (before contact formation) lapped Si surface. In that case, the calculated and experimental dependences $\rho_{c}(T)$ practically coincided $[27,28]$.

Contact metallization in silicon microelectronic devices is formed, as a rule, on polished surface of heavily doped $\mathrm{Si}$. According to the known models for contacts to heavily doped $\mathrm{Si}$ layers, a very slight reduction of $\rho_{c}$ with temperature would be observed there. However, the existing data indicate a possibility of appearance of a high density of structural defects among the dislocations (with the density up to $10^{9} \mathrm{~cm}^{-2}$ ) in these contact structures. These are dislocations parallel to the interface, as well as those crossing the space charge region etc. The prepared specimens may also demonstrate dependence $\rho_{c}(T)$ growing with temperature.

Therefore, it seemed expedient to study in detail temperature dependence $\rho_{c}(T)$ for ohmic contacts to the standard substrate material used in the manufacturing technology for Si microwave diodes (e.g., $n^{+}$- Si with the resistivity $\sim 0.002 \Omega \cdot \mathrm{cm})$. The objective of our work is to elucidate the role of defect structure of metallization and near-surface silicon region both before and after thermal annealing (contact firing modes).

\section{Specimens and methods of investigation}

We studied the $\mathrm{Au}-\mathrm{Ti}-\mathrm{Pd}-n^{+}-\mathrm{Si}$, $\mathrm{Au}-\mathrm{Pt}-\mathrm{Pd}-n^{+}-\mathrm{Si}$ and $\mathrm{Au}-\mathrm{Pt}-\mathrm{Ti}-\mathrm{Pd}-n^{+}-\mathrm{Si}$ ohmic contacts made using layer-by-layer vacuum thermal deposition of metal onto heated up to $300{ }^{\circ} \mathrm{C} \mathrm{Si}$ (111) wafers of about $300 \mu \mathrm{m}$ thick, doped with arsenic (with the resistivity $\sim 0.002 \Omega \cdot \mathrm{cm}$ ). The $10 \times 10 \mathrm{~mm}^{2}$ specimens with continuous metallization were used for structural and morphological investigations. To measure temperature dependences $\rho_{c}(T)$ in the 100 to $380 \mathrm{~K}$ range, test transmission line method (TLM) structures were used. The specimens of both above types were investigated before and after annealing in vacuum (pressure $\sim 10^{-4} \mathrm{~Pa}$ ) at 400 and $450{ }^{\circ} \mathrm{C}$ for $10 \mathrm{~min}$.

The component concentration depth profiles in metallization layers and at contact-forming layer-silicon interfaces were measured on the specimens with continuous metallization using Auger spectrometry with a spectrometer LAS-2000. The phase composition of contact metallization was studied using the X-ray diffraction (XRD) technique with an X-ray diffractometer Philips X'Pert-MRD $\left(\mathrm{Cu}_{K \alpha}=\right.$ $0.15418 \mathrm{~nm}$ ) in the Bragg-Brentano geometry. The morphological features of Si surface were investigated with an atomic-force microscope Nanoscope-IIIa (Digital Instruments, USA).

After chemical removal of metallization layers, silicon surface was etched in selective Wright etch at room temperature for $90 \mathrm{~s}$ to detect etch pits associated with structural defects, in particular, dislocations. The investigations of specimen surfaces (after removal of metallization and selective etching) as well as specimen cleavages with deposited metal films were performed using a high resolution scanning electron microscope (SEM) S-4800 (Hitachi, Japan). The elemental composition of metal films and microinclusions in $\mathrm{Si}$ was determined with an energy dispersive X-ray spectrometer Quantax 200 with XFlash 5030 Detector (Bruker AXS, Germany). 


\section{Experimental results and discussion}

\section{A. X-ray diffraction studies}

$A u-T i-P d-n^{+}-S i$. Fig. 1 presents the XRD spectra of $\mathrm{Au}-\mathrm{Ti}-\mathrm{Pd}-n^{+}-\mathrm{Si}$ contact metallization taken before and after annealing at 400 and $450{ }^{\circ} \mathrm{C}$ for $10 \mathrm{~min}$. One can see that the phase composition of the contact system under investigation (both initial specimen and those annealed at $400{ }^{\circ} \mathrm{C}$ ) practically did not change. It involved the $\mathrm{Pd}_{2} \mathrm{Si}$ phase and $\mathrm{Au}$. The XRD spectra also had reflections from Si (curves 1 and 2, respectively). In the course of annealing at $450{ }^{\circ} \mathrm{C}$ for $10 \mathrm{~min}$ (curve 3 ), the $\mathrm{Au}_{2} \mathrm{Si}$ and $\mathrm{Pd}_{100-x} \mathrm{Si}_{x}$ phases appeared in addition to those available. The contact became nonuniform as compared to the previous two states (initial and after annealing at $400^{\circ} \mathrm{C}$ for $10 \mathrm{~min}$ ).

$A u-P t-P d-n^{+}-S i$. The XRD spectrum of contact metallization on the initial specimen involved reflections from polycrystalline metals $\mathrm{Au}, \mathrm{Pt}$ and $\mathrm{Pd}$. Annealing at $400{ }^{\circ} \mathrm{C}$ for $10 \mathrm{~min}$. led to formation of the $\mathrm{Pd}_{2} \mathrm{Si}$ phase. Along with that phase, platinum and gold silicides appeared after annealing at $450{ }^{\circ} \mathrm{C}$ for $10 \mathrm{~min}$. Formation of Au-based solid solution that involved $\mathrm{Au}$, $\mathrm{Pt}, \mathrm{Pd}$ and $\mathrm{Si}$ was also observed. According to the literature data [29], such a composition of contact metallization has to result in a nonuniform contact layer-Si interface.

$A u-P t-T i-P d-n^{+}-S i$. The XRD spectra of the initial contact demonstrated a set of reflections only from $\mathrm{Au}$ and $\mathrm{Pt}$ metallization. It indicates the polycrystalline structure of individual metal layers (curve 1 in Fig. 2). The XRD spectrum of contact annealed at $400^{\circ} \mathrm{C}$ for $10 \mathrm{~min}$, along with reflections from $\mathrm{Au}$ and $\mathrm{Pt}$ metallization, had $\mathrm{Pd}$ and $\mathrm{Ti}$ reflections (curve 2 in Fig. 2). It is indicative of the transition from initial X-ray amorphous $\mathrm{Pd}$ and $\mathrm{Ti}$ layers to polycrystalline ones in the course of annealing. Further annealing at $450{ }^{\circ} \mathrm{C}$ led to appearance of the $\mathrm{Pd}_{2} \mathrm{Si}$ phase, while the reflections from Pt disappeared (curve 3 in Fig. 2).

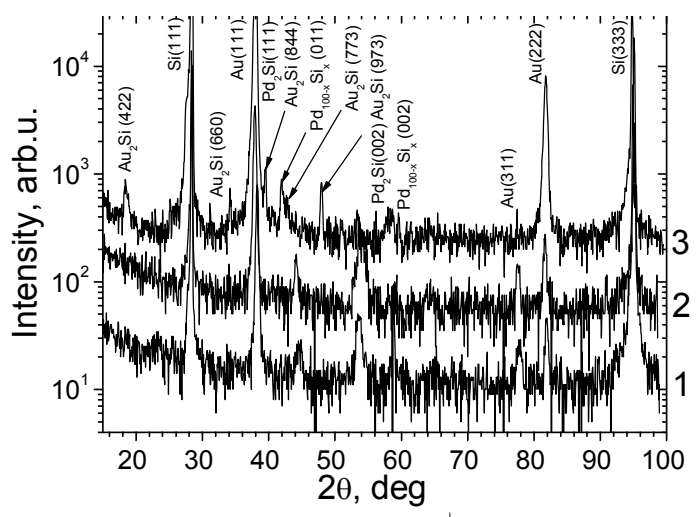

Fig. 1. XRD spectra of $\mathrm{Au}-\mathrm{Ti}-\mathrm{Pd}-n^{+}-\mathrm{Si}$ contact metallization before (1) and after annealing at $400{ }^{\circ} \mathrm{C}(2)$ and $450{ }^{\circ} \mathrm{C}$ (3) for $10 \mathrm{~min}$.

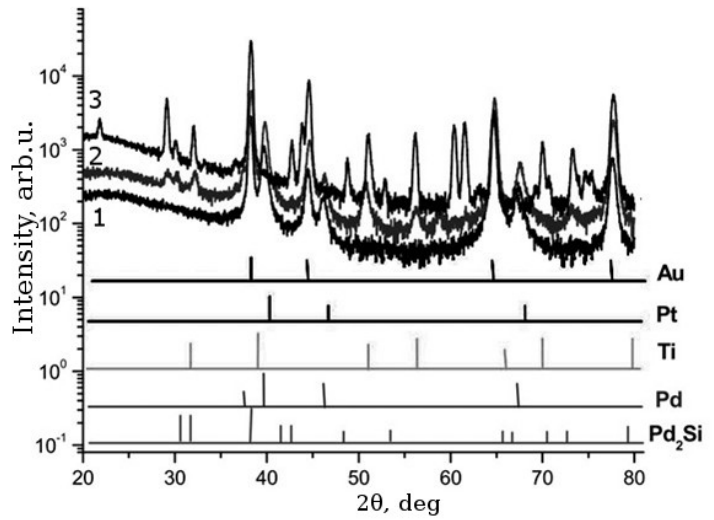

Fig. 2. XRD spectra of $\mathrm{Au}-\mathrm{Pt}-\mathrm{Ti}-\mathrm{Pd}-n^{+}-\mathrm{Si}$ contact metallization before (1) and after annealing at $400{ }^{\circ} \mathrm{C}(2)$ and $450{ }^{\circ} \mathrm{C}(3)$ for $10 \mathrm{~min}$.

\section{B. Concentration depth profiles of metallization components}

$\underline{A u-T i-P d-n^{+}-S i}$. Shown in Figs 3a, b are the concentration depth profiles of the contact metallization components before and after annealing at $450{ }^{\circ} \mathrm{C}$ for $10 \mathrm{~min}$. One can see (Fig. 3a) that the silicide phase is formed in the course of Pd deposition. The Ti film contains a rather big amount of oxygen (over 10\%) and carbon $(\sim 8-10 \%)$. The $\mathrm{Au}$ film is enriched up to $20 \%$ with oxygen at the interface with Ti. Annealing this contact metallization at $400{ }^{\circ} \mathrm{C}$ for 10 min does not change its layered structure considerably. Intensification of silicides formation at the $\mathrm{Pd}-\mathrm{Si}$ interface is proceeding in the course of annealing at $450{ }^{\circ} \mathrm{C}$ for 10 min. A "step" appears in the Si concentration depth profile (Fig. 3b). Mass transfer of titanium into gold film as well as gold to the interface with silicon was also observed. The above results are in good agreement with the XRD data (Fig. 1).

$A u-P t-P d-n^{+}-S i$. Figs $4 a-c$ and 5 a-c present the concentration depth profiles of the contact metallization components and a map of elements distribution over the specimen end (vertical cleavage). One can see that the initial specimen has the metallization with a typical layered structure (Figs $4 \mathrm{a}$ and 5a). Annealing at $400{ }^{\circ} \mathrm{C}$ for 10 min leads to considerable smearing the $\mathrm{Au}-\mathrm{Pt}$ and $\mathrm{Pt}-\mathrm{Si}$ interfaces and $\mathrm{Pd}$ mass transfer into $\mathrm{Si}$ and $\mathrm{Pt}$. It is also shown on the map of elements distribution (Figs $4 \mathrm{~b}$ and $5 \mathrm{~b}$ ). After annealing at $450{ }^{\circ} \mathrm{C}$ for $10 \mathrm{~min}$, the layered structure of contact metallization deteriorates, and interpenetration of metal and Si to the corresponding regions of contact structure is observed (Fig. 4c). In this case, the near-contact region of silicon becomes essentially nonuniform (Fig. 5c).

It should be noted that the characteristic distinction between the $\mathrm{Au}-\mathrm{Pt}-\mathrm{Pd}-n^{+}-\mathrm{Si}$ and $\mathrm{Au}-\mathrm{Ti}-\mathrm{Pd}-n^{+}-\mathrm{Si}$ contact metallizations is a slight amount (practically complete absence) of oxygen and carbon in the $\mathrm{Au}-\mathrm{Pt}-\mathrm{Pd}-n^{+}-\mathrm{Si}$ contact. 

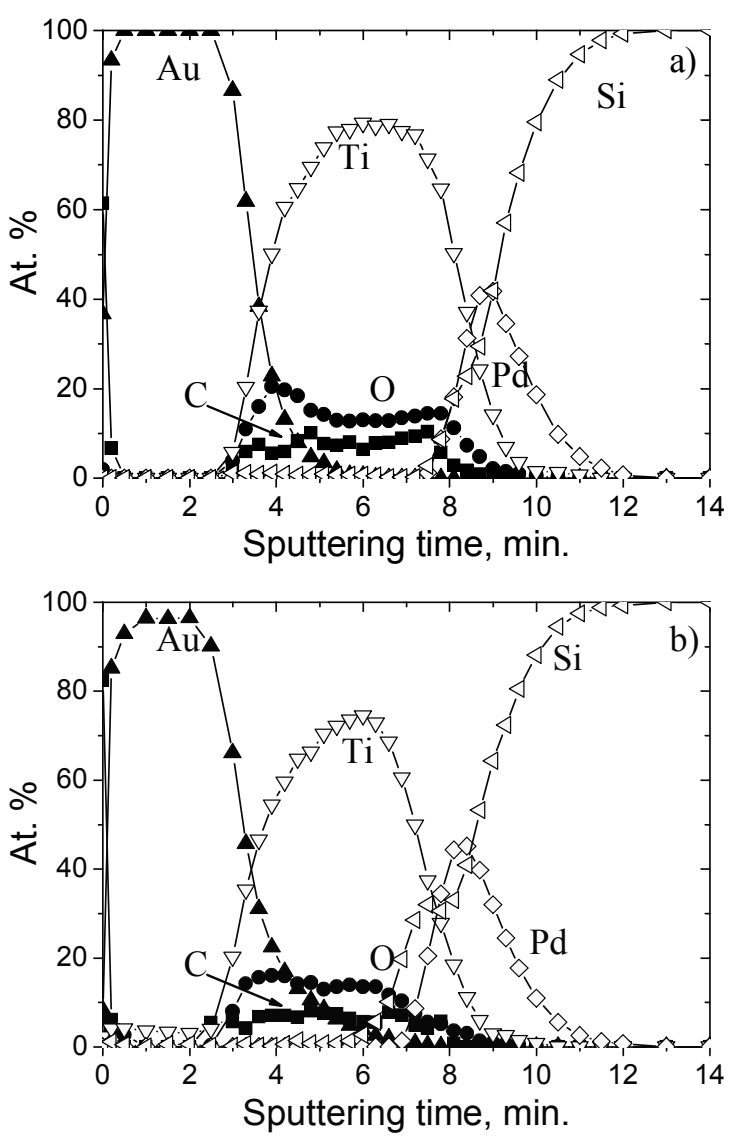

Fig. 3. Concentration depth profiles of metallization components in $\mathrm{Au}-\mathrm{Ti}-\mathrm{Pd}-n^{+}-\mathrm{Si}$ ohmic contact before $(a)$ and after $(b)$ annealing at $450{ }^{\circ} \mathrm{C}$ for $10 \mathrm{~min}$.

$\underline{A u-P t-T i-P d-n^{+}-S i}$. The concentration depth profiles of the $\mathrm{Au}-\mathrm{Pt}-\mathrm{Ti}-\mathrm{Pd}-n^{+}-\mathrm{Si}$ contact metallization components taken before and after annealing at $450{ }^{\circ} \mathrm{C}$ for $10 \mathrm{~min}$, as well as scanning electron microscope (SEM) photographs of vertical cleavages of the contact structures before and after annealing at 400 and $450{ }^{\circ} \mathrm{C}$ for 10 min are presented in Figs $6 \mathrm{a}, \mathrm{b}$ and $7 \mathrm{a}, \mathrm{b}$, respectively. One can see that initial contact metallization has a layered structure. The titanium film contains over $10 \%$ oxygen and carbon (Fig. 6a).

The layered structure of metallization deteriorates in the course of annealing at $450{ }^{\circ} \mathrm{C}$ for 10 min (Fig. 6b). $\mathrm{Si}, \mathrm{Pt}$ and $\mathrm{Pd}$ atoms (up to 50 at.\% $\mathrm{Si}$ and more than 10 at.\% $\mathrm{Pt}$ and $\mathrm{Pd}$ ) penetrate through all the metallization layers to the external contact surface. The internal surface of the near-contact region on the Si side contains a considerable amount of $\mathrm{Ti}, \mathrm{Au}$ and $\mathrm{Pt}$. Judging from the presence of the "steps" in the concentration depth profiles, the corresponding silicide phases may be formed in the metallization layers. This conclusion is in agreement with the XRD data obtained for this specimen (Fig. 2, curve 3).
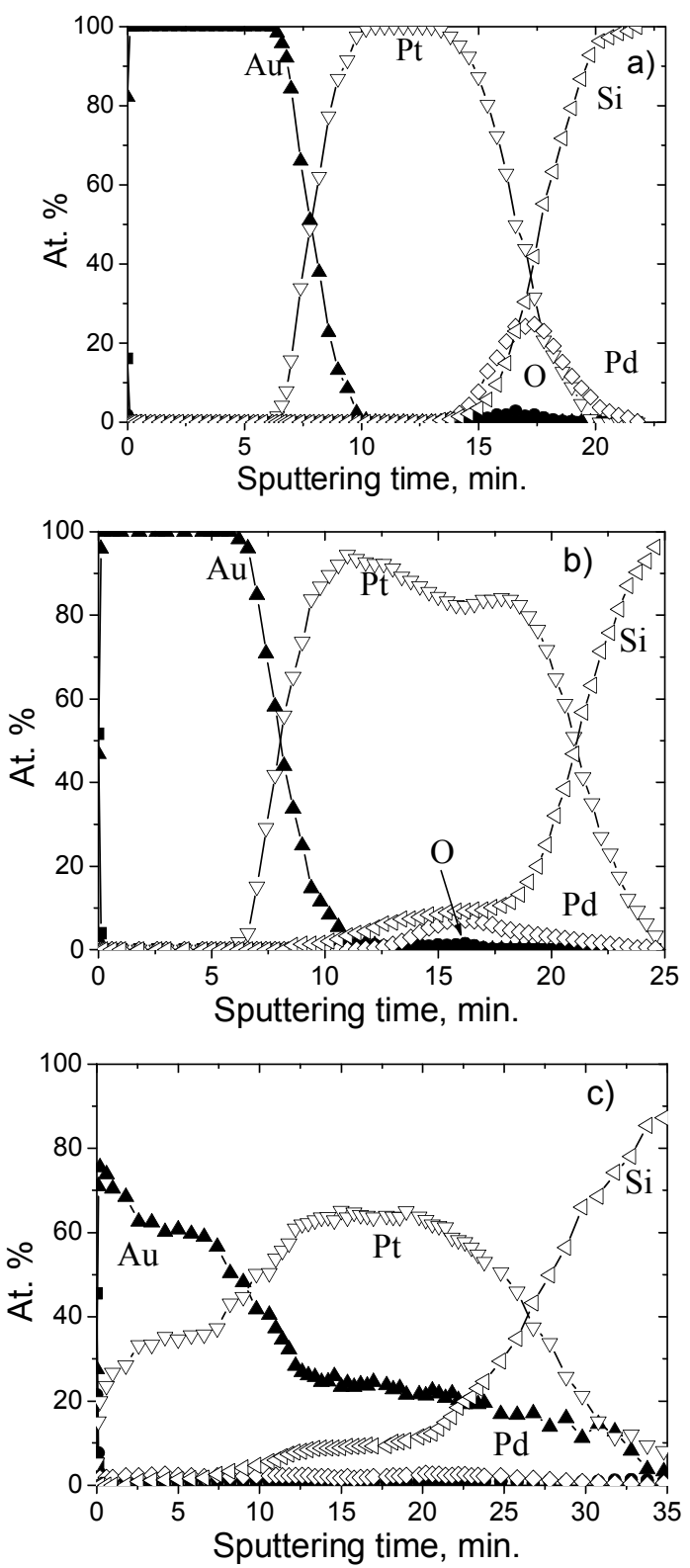

Fig. 4. Concentration depth profiles of metallization components in $\mathrm{Au}-\mathrm{Pt}-\mathrm{Pd}-n^{+}-\mathrm{Si}$ ohmic contact before (a) and after annealing at $400^{\circ} \mathrm{C}(\mathrm{b})$ and $450^{\circ} \mathrm{C}$ (c) for $10 \mathrm{~min}$.

The results obtained with Auger spectrometry are confirmed by the morphological features of vertical cleavages on the initial and annealed specimens. Fig. 7a presents a SEM photograph of the vertical cleavage of the initial specimen, with a rather abrupt contact-forming layer-Si interface. After annealing the specimen at $450{ }^{\circ} \mathrm{C}$ for $10 \mathrm{~min}$, one can see a columnar metallization structure in the SEM photograph of the cleavage (Fig. 7c). Its elemental composition and SEM photograph of the cleavage are presented in Figs 8a, b. The spectral characteristic of the columnar structure was obtained from five columnar inclusions. It follows from Fig. $8 \mathrm{~b}$ that the elemental composition of the analyzed column, along with $\mathrm{Si}$, also involves $\mathrm{Pt}$ and $\mathrm{Au}$. 


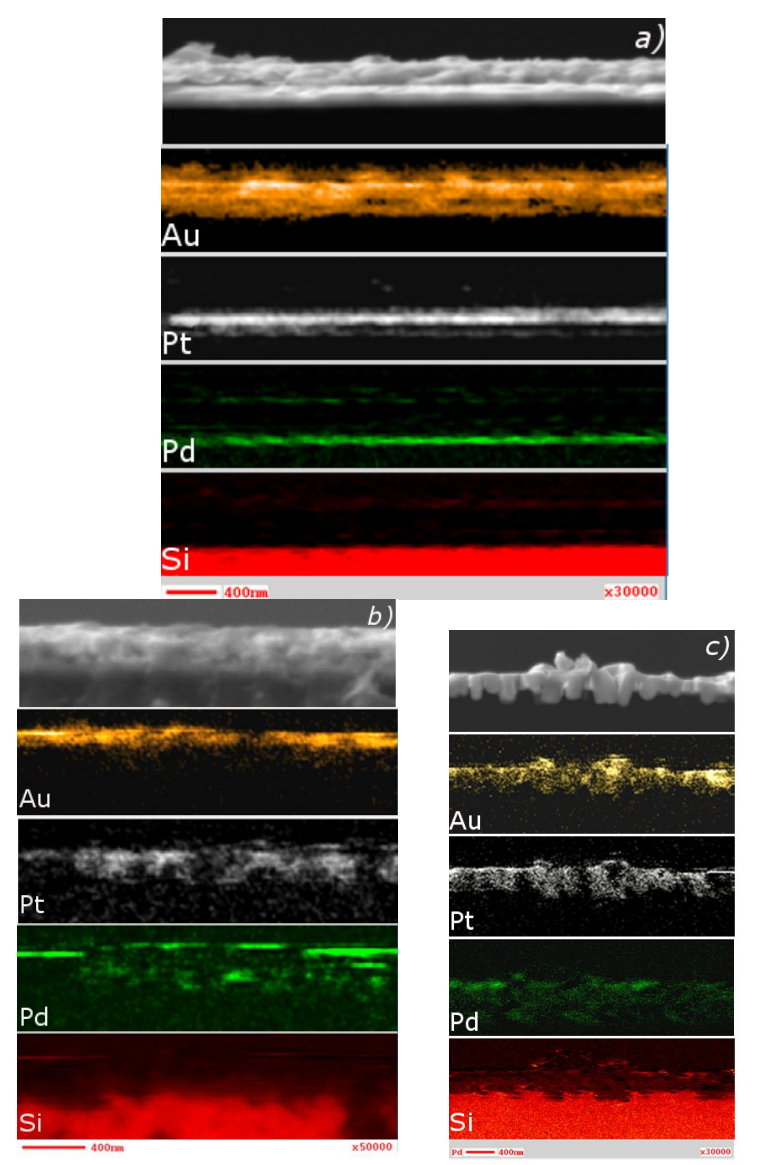

Fig. 5. Metallization component maps for $\mathrm{Au}-\mathrm{Pt}-\mathrm{Pd}-n^{+}-\mathrm{Si}$ ohmic contact before $(a)$ and after annealing at $400{ }^{\circ} \mathrm{C}(b)$ and $450{ }^{\circ} \mathrm{C}(c)$ for $10 \mathrm{~min}$.

\section{Morphological features of Si surface after removal of metallization layers}

$\mathrm{Au}-\mathrm{Ti}-\mathrm{Pd}-n^{+}-\mathrm{Si}$. After removal of metallization layers with chemical etching, the Si surface was studied using atomic force microscopy. Table 1 presents the data on roughness for $2 \times 2 \mu \mathrm{m}^{2}$ (un)annealed specimens. One can see that, after removal of metallization, the microreliefs of the initial non-metallized and Si surfaces differ considerably. A developed roughness indicates the process of interaction between Pd and Si that appears at $\mathrm{Pd}$ deposition and is activated at annealing. It correlates with the data of XRD and Auger electron spectrometry.

$A u-P t-P d-n^{+}-S i$. The SEM photographs (Figs 911) present the morphological features of the Au-Pt-Pd metallization layers surfaces and the metal-Si interface (taken before and after annealing at 400 and $450{ }^{\circ} \mathrm{C}$ for $10 \mathrm{~min}$ ) obtained using successive ion etching. One can see from Figs $9 a-c$ and $10 a-c$ that the metal layers of the initial and annealed contact structures have microstructures that differ but slightly. They are characterized by comparatively uniform distribution of grains of the same size. The contact-forming layer-silicon interface (representing per se Si surface) in the initial specimen has smaller grains than those in the specimen annealed at $400{ }^{\circ} \mathrm{C}$ for $10 \mathrm{~min}$ (Figs $9 \mathrm{~d}$ and 10d). It indicates interaction between the phases in that region, occurring at Pd film deposition and in the course of further annealing.

The above processes proceed more intensely in the course of annealing at $450^{\circ} \mathrm{C}$ for $10 \mathrm{~min}$ (Fig. $11 \mathrm{a}-\mathrm{e}$ ). A nonuniform block structure (linear block sizes from fractions of micrometer up to $1 \ldots 1.5 \mu \mathrm{m}$ ) appears on the $\mathrm{Au}$ film surface (Fig. 11a). The subsequent, more dense large-grain structures represent the region of $\mathrm{AuPt}$ mixing and Pt layer (Fig. 11b, c, respectively) as well as a microstructure of the region of $\mathrm{Pd}$ and $\mathrm{Si}$ mixing (Fig. 11e).

After removal of metallization, the Si surface (see Fig. 11e) contains free Si surface and individual small inclusions. The results of our analysis of the inclusions elemental composition at five points are summarized in Table 2. Shown in Fig. 12 is a SEM photograph of $\mathrm{Si}$ surface after removal of metallization; indicated are the points for which an analysis of the inclusions elemental composition was made. One can conclude that interpenetration of metals and silicon occurs over the whole thickness of metallization, up to detection of gold on $\mathrm{Si}$ surface and mass transport of silicon into metallization layers. The latter is supported by the results of the elemental analysis of Au film surface in the $\mathrm{Au}-\mathrm{Pt}-\mathrm{Pd}-n^{+}-\mathrm{Si}$ contact metallization after annealing at $450{ }^{\circ} \mathrm{C}$ for $10 \mathrm{~min}$.
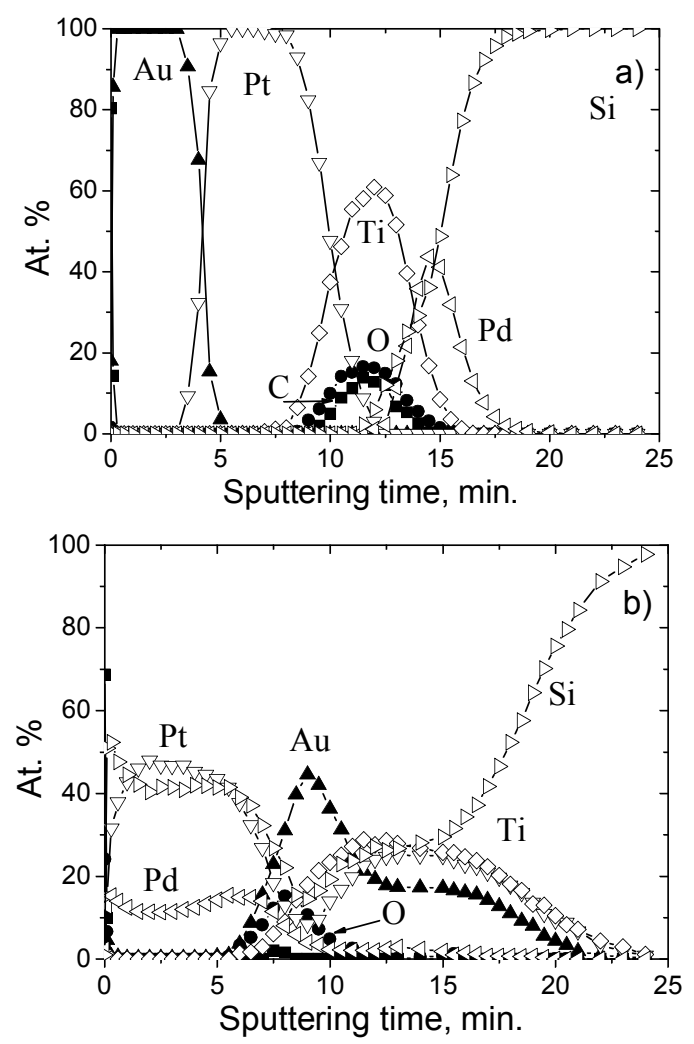

Fig. 6. Concentration depth profiles of metallization components in $\mathrm{Au}-\mathrm{Pt}-\mathrm{Ti}-\mathrm{Pd}-n^{+}-\mathrm{Si}$ ohmic contact before $(a)$ and after $(b)$ annealing at $450{ }^{\circ} \mathrm{C}$ for $10 \mathrm{~min}$. 

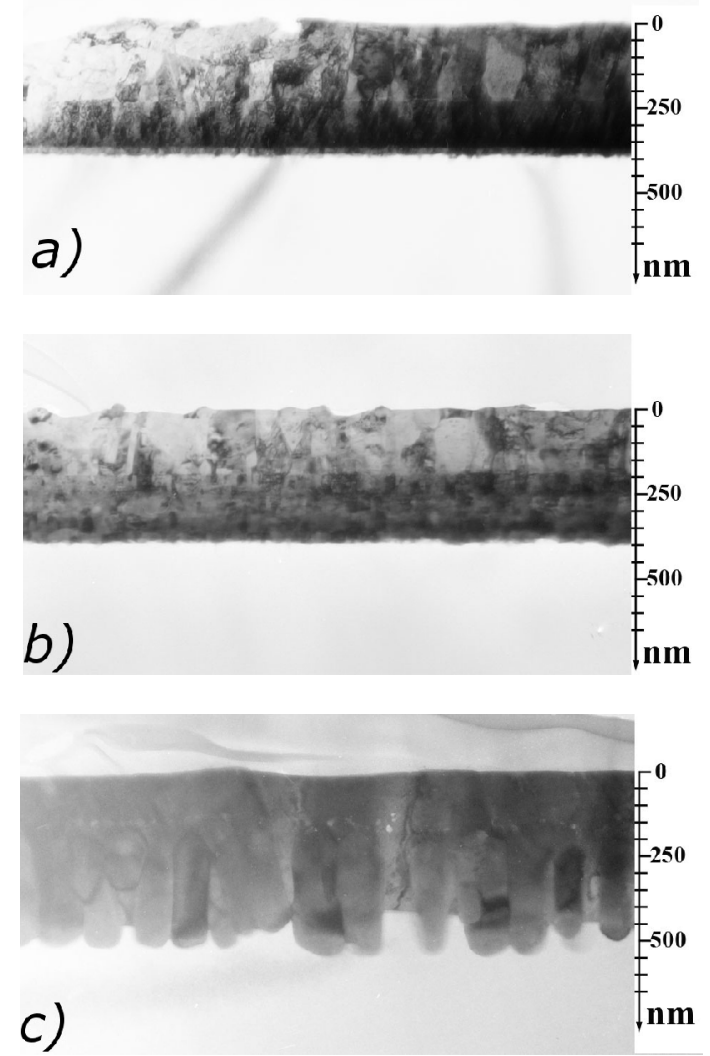

Fig. 7. SEM photograph of vertical cleavages in $\mathrm{Au}-\mathrm{Pt}-\mathrm{Ti}-\mathrm{Pd}-n^{+}-\mathrm{Si}$ contact structures before $(a)$ and after annealing at $400{ }^{\circ} \mathrm{C}(b)$ and $450{ }^{\circ} \mathrm{C}(c)$ for $10 \mathrm{~min}$.

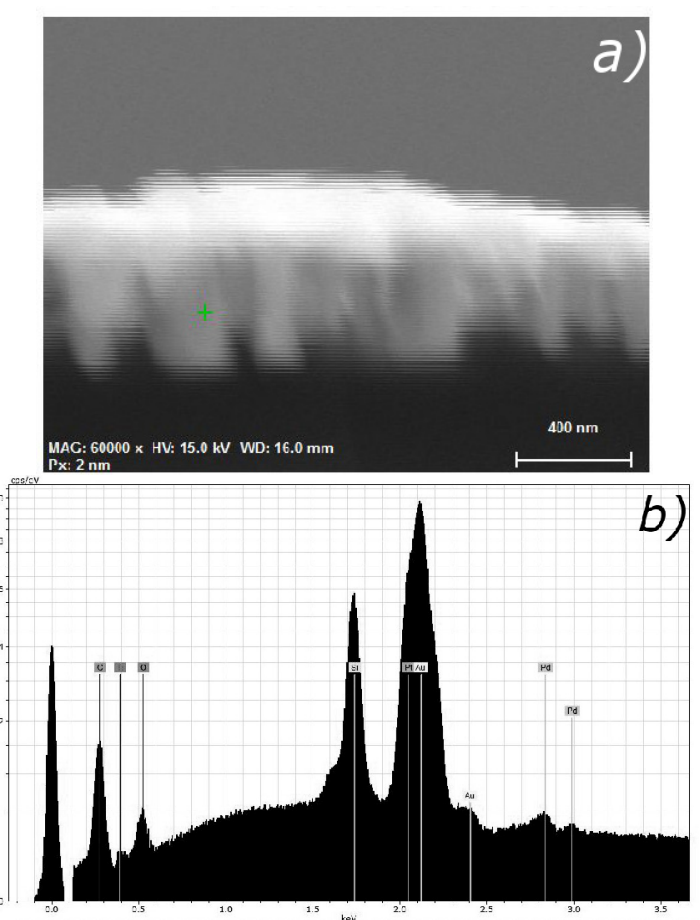

Fig. 8. SEM photograph of the cleavage fragment $(a)$ and elemental composition $(b)$ of $\mathrm{Au}-\mathrm{Pt}-\mathrm{Ti}-\mathrm{Pd}-n^{+}-\mathrm{Si}$ contact structure after annealing at $450{ }^{\circ} \mathrm{C}$ for $10 \mathrm{~min}$.
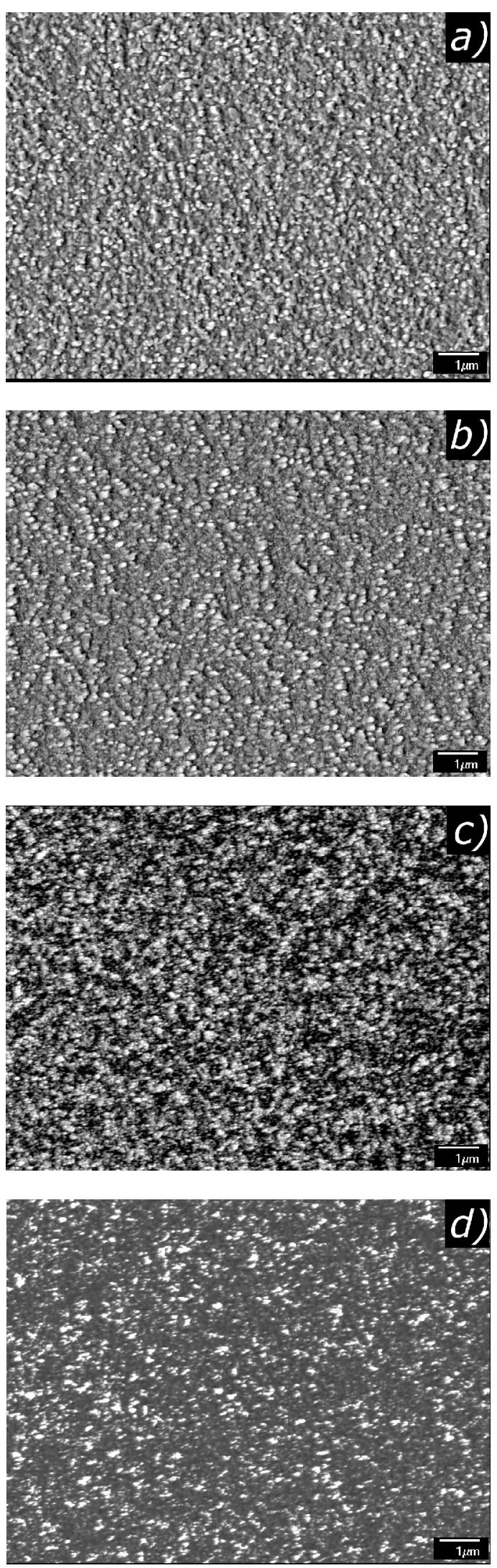

Fig. 9. SEM photograph of surface morphology of $\mathrm{Au}(a)$, $\mathrm{Pt}(b), \mathrm{Pd}(c)$ and $\mathrm{Si}(d)$ layers in the $\mathrm{Au}-\mathrm{Pt}-\mathrm{Pd}-n^{+}-\mathrm{Si}$ contact structure before annealing.

(C) 2013, V. Lashkaryov Institute of Semiconductor Physics, National Academy of Sciences of Ukraine 

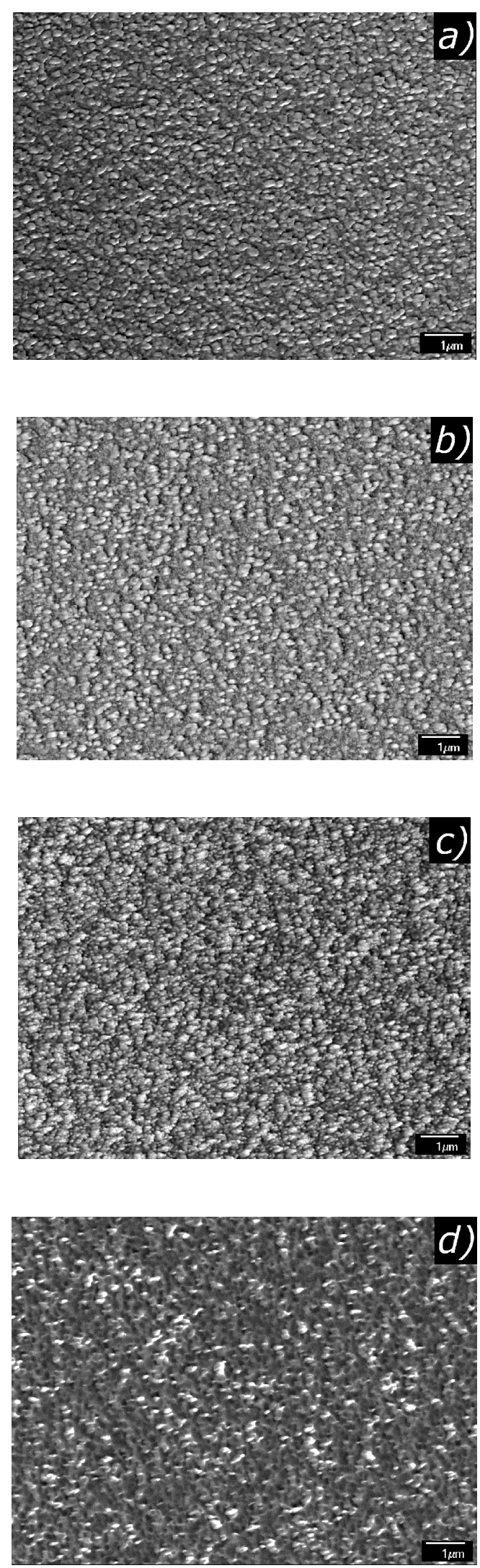

Fig. 10. SEM photograph of surface morphology of $\mathrm{Au}(a)$, $\mathrm{Pt}(b), \mathrm{Pd}(c)$ and $\mathrm{Si}(d)$ layers in the $\mathrm{Au}-\mathrm{Pt}-\mathrm{Pd}-n^{+}-\mathrm{Si}$ contact structure after annealing at $400{ }^{\circ} \mathrm{C}$ for $10 \mathrm{~min}$.
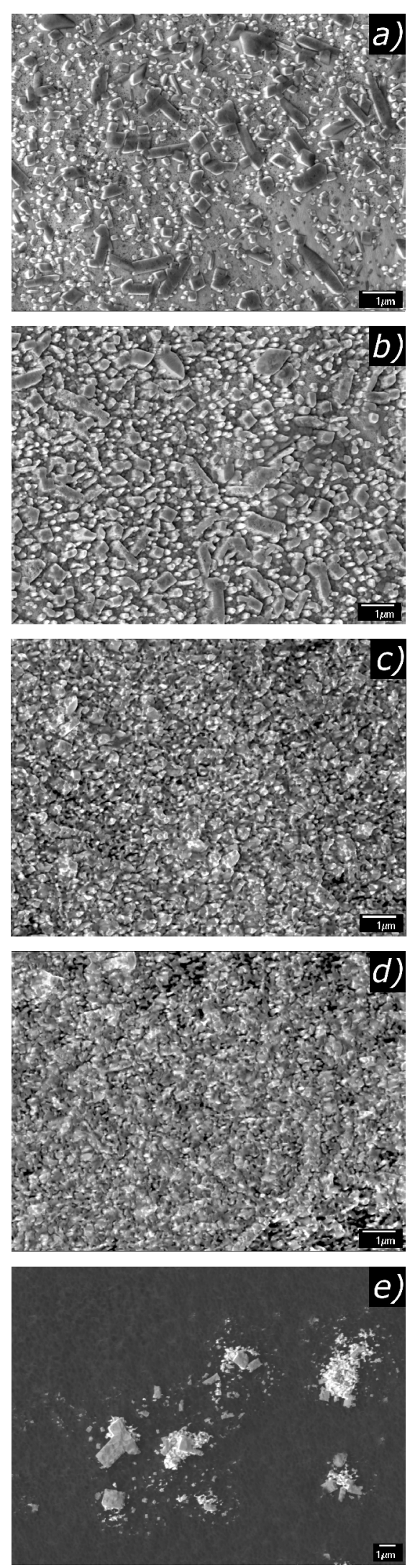

Fig. 11. SEM photograph of surface morphology of $\mathrm{Au}(a)$, $\mathrm{AuPt}(b), \mathrm{Pt}(c), \mathrm{Pd}(d)$ and $\mathrm{Si}(e)$ layers in the $\mathrm{Au}-\mathrm{Pt}-\mathrm{Pd}-n^{+}-$ Si contact structure after annealing at $450{ }^{\circ} \mathrm{C}$ for $10 \mathrm{~min}$. 


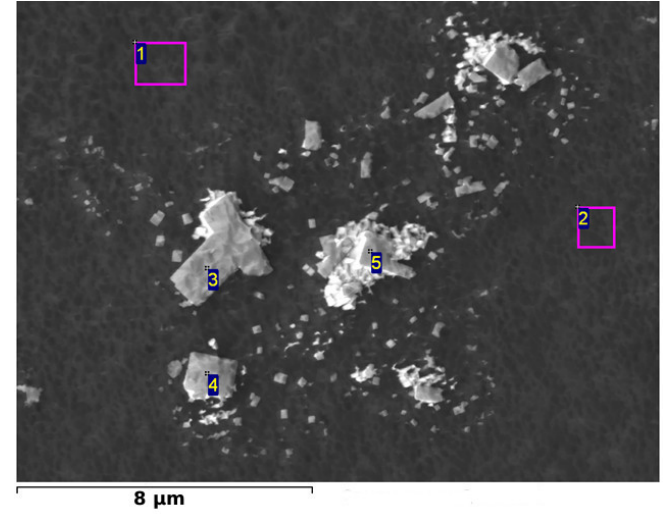

Fig. 12. SEM photograph of Si surface after removal of $\mathrm{Au}-\mathrm{Pt}-\mathrm{Pd}$ metallization (indicated are the points for which an analysis of the inclusions elemental composition was made).

A SEM photograph of Au surface, with indicated points at which an analysis of the film elemental composition was made, is presented in Fig. 13. Table 3 presents the data on the Au film elemental composition determined at six points. The points 1-3 contain over $40 \% \mathrm{Si}$, over $5 \% \mathrm{Pd}$ and less than $45 \% \mathrm{Pt}$. These (and similar) regions in Fig. 13 are dark. The light-colored regions (points 4-6) contain over 94\% Au; however, they contain also $\mathrm{Si}(4.26,2.89$ and 1.56 at.\%) and a small amount of Pd (see point 5).

The above data show that, being annealed at $400{ }^{\circ} \mathrm{C}$ for $10 \mathrm{~min}$, the Pt layer cannot prevent mass transfer in the $\mathrm{Au}-\mathrm{Pt}-\mathrm{Pd}-n^{+}-\mathrm{Si}$ metallization layers and does not serve as a diffusion barrier. The metallized regions localized at the interface with Si cause formation of a nonuniform ohmic contact - metal shunts penetrating through silicon. Their role in formation of ohmic contacts was considered as a working hypothesis in [17-20,23]. Its validity was proved in [25] at experimental investigation of temperature dependence of contact resistivity using ohmic contacts to $n$-GaN with a high dislocation density as an example.

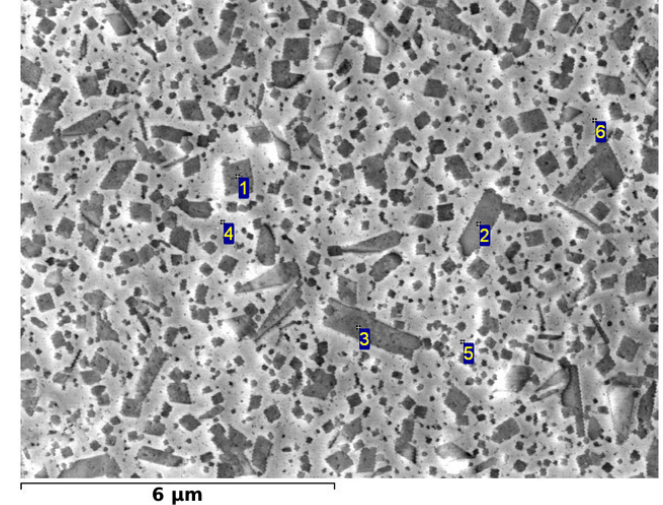

Fig. 13. SEM photograph of Au film surface in $\mathrm{Au}-\mathrm{Pt}-\mathrm{Pd}-n^{+}-$ Si contact metallization after annealing at $450{ }^{\circ} \mathrm{C}$ for $10 \mathrm{~min}$ (indicated are the points for which an analysis of the inclusions elemental composition was made).

$\mathrm{Au}-\mathrm{Pt}-\mathrm{Ti}-\mathrm{Pd}-n^{+}-\mathrm{Si}$. Our analysis of the morphological features of the $\mathrm{Si}$ near-contact region before and after annealing at $400{ }^{\circ} \mathrm{C}$ for 10 min showed that there was no essential changes of the dislocation density (it was $\sim 10^{4} \mathrm{~cm}^{-2}$ in the initial $n^{+}-\mathrm{Si}$ substrate). Fig. 14 shows Si surface (after removal of metallization and selective chemical etching with Wright etch) of a specimen annealed at $450{ }^{\circ} \mathrm{C}$ for $10 \mathrm{~min}$. Judging from the features of defects, the structural defects with the density over $10^{10} \mathrm{~cm}^{-2}$ (among them dislocation loops) are localized in a thin near-contact layer of silicon. They may appear due to relaxation of intrinsic stresses in contacts, for which contact-forming layers and silicon have very different values of both the lattice parameter $a$ and the coefficient of thermal expansion $\alpha$ [29-33]. Another possible reason for their appearance may be relaxation of stresses related to local stress raisers $[8,12]$.

Table 4 presents the literature data on the above parameters for the phases detected with the XRD technique in the contact structure under investigation. One can see that for most of the silicide phases

Table 1. The features of Si surface microrelief after removal of metallization from the initial and annealed specimens.

\begin{tabular}{|c|c|c|c|}
\hline Parameter & Initial specimen & $\begin{array}{c}\text { After annealing at } 450{ }^{\circ} \mathrm{C} \text { for } \\
10 \text { min }\end{array}$ & $\begin{array}{c}\text { Initial } n^{+} \text {-Si substrate (epi- } \\
\text { ready) }\end{array}$ \\
\hline RMS, nm & 8.86 & 12.41 & 0.30 \\
$R_{a}, \mathrm{~nm}$ & 16.49 & 23.82 & 0.17 \\
$Z_{\max }, \mathrm{nm}$ & 78.12 & 93.90 & 0.60 \\
\hline
\end{tabular}

RMS - root-mean-square roughness; $R_{a}$ - arithmetical mean roughness; $Z_{\max }$ - maximal height of surface roughness.

Table 2. Elemental composition of five local areas at the contact-forming layer-Si interface.

\begin{tabular}{|c|c|c|c|c|}
\hline \multirow{2}{*}{ Point \# } & \multicolumn{4}{|c|}{ Elemental atomic \% } \\
\cline { 2 - 4 } & $\mathrm{Si}$ & $\mathrm{Pd}$ & $\mathrm{Pt}$ & $\mathrm{Au}$ \\
\hline 1 & 99.88 & 0.06 & 0.00 & 0.06 \\
2 & 99.85 & 0.00 & 0.05 & 0.11 \\
3 & 52.78 & 2.71 & 44.51 & 0.00 \\
4 & 49.04 & 4.73 & 46.23 & 0.00 \\
5 & 49.09 & 4.56 & 46.35 & 0.00 \\
\hline
\end{tabular}


Table 3. Elemental composition in the local areas of $\mathrm{Au}$ film in $\mathrm{Au}-\mathrm{Pt}-\mathrm{Pd}-\boldsymbol{n}^{+}-\mathrm{Si}$ metallization after annealing at $450{ }^{\circ} \mathrm{C}$ for $10 \mathrm{~min}$.

\begin{tabular}{|c|c|c|c|c|}
\hline \multirow{2}{*}{ Point \# } & \multicolumn{4}{|c|}{ Elemental atomic \% } \\
\cline { 2 - 5 } & $\mathrm{Si}$ & $\mathrm{Pd}$ & $\mathrm{Pt}$ & $\mathrm{Au}$ \\
\hline 1 & 45.62 & 6.34 & 45.02 & 3.03 \\
2 & 41.66 & 6.89 & 38.41 & 13.03 \\
3 & 43.47 & 5.73 & 41.20 & 9.60 \\
4 & 4.26 & 0.00 & 0.00 & 95.74 \\
5 & 2.89 & 2.92 & 0.00 & 94.20 \\
6 & 1.56 & 0.00 & 0.00 & 98.44 \\
\hline
\end{tabular}

Table 4. Some parameters of metal layers and intermetallics appearing in the Au-Pt-Ti-Pd- $\boldsymbol{n}^{+}$-Si contact [29-33].

\begin{tabular}{|c|c|c|c|c|c|c|c|c|c|}
\hline \multirow{2}{*}{ Metal } & \multicolumn{3}{|c|}{ Lattice parameter, $\mathbf{n m}$} & \multirow{2}{*}{ Structure } & \multirow{2}{*}{$\begin{array}{c}\text { Lattice } \\
\text { mis- } \\
\text { match } \\
\text { para- } \\
\text { meter } f\end{array}$} & \multirow{2}{*}{$\begin{array}{c}\text { Coefficient of } \\
\text { thermal } \\
\text { expansion } \alpha \\
\mathrm{K}^{-1}\end{array}$} & \multirow{2}{*}{$\begin{array}{c}\text { Phase } \\
\text { formation } \\
\text { tempera- } \\
\text { ture, }{ }^{\circ} \mathrm{C}\end{array}$} & \multirow{2}{*}{$\begin{array}{c}\text { Young's } \\
\text { modulus, } \\
\text { GPa }\end{array}$} & \multirow{2}{*}{$\begin{array}{c}\text { Poisson } \\
\text { ratio }\end{array}$} \\
\hline & $a$ & $b$ & $c$ & & & & & & \\
\hline $\mathrm{Pd}$ & 0.389 & & & FCC & -0.28 & $\begin{array}{c}11.75 \times 10^{-6} \\
13 \times 10^{-6}\end{array}$ & & $115-125$ & 0.39 \\
\hline $\mathrm{Ti}$ & 0.323 & & 0.5106 & hexagonal & -0.4 & $8.3 \times 10^{-6}$ & & 110 & 0.33 \\
\hline $\mathrm{Pt}$ & 0.392 & & & FCC & -0.27 & $8.99 \times 10^{-6}$ & & $150-175$ & 0.36 \\
\hline $\mathrm{Au}$ & 0.408 & & & FCC & -0.24 & $14 \times 10^{-6}$ & & $78-83$ & 0.4 \\
\hline $\mathrm{Si}$ & 0.543 & & & diamond & & $2.54 \times 10^{-6}$ & & $110-160$ & 0.28 \\
\hline $\mathrm{Pd}_{2} \mathrm{Si}$ & 1.3055 & & 2.749 & hexagonal & 1.4 & & $100-300$ & & \\
\hline $\mathrm{Pd}_{3} \mathrm{Si}$ & 0.5735 & 0.7555 & 0.5260 & $\begin{array}{c}\text { rhombo- } \\
\text { hedral }\end{array}$ & 0.056 & & 350 & & \\
\hline $\mathrm{PdSi}$ & 0.5599 & 0.3381 & 0.6133 & $\begin{array}{c}\text { rhombo- } \\
\text { hedral }\end{array}$ & 0.03 & & 800 & & \\
\hline $\mathrm{Pd}_{3} \mathrm{Ti}$ & 0.548 & & 0.8976 & & & & & & \\
\hline $\mathrm{PtSi}$ & 0.559 & 0.3603 & 0.5932 & $\begin{array}{c}\text { rhombo- } \\
\text { hedral }\end{array}$ & 0.03 & & $225-300$ & & \\
\hline $\mathrm{Pt}_{3} \mathrm{Si}$ & 0.546 & & 0.786 & tetragonal & 0.0055 & & 400 & & \\
\hline $\mathrm{Au}_{5} \mathrm{Si}_{2}$ & 0.9406 & & 1.5487 & hexagonal & 0.73 & & & & \\
\hline $\mathrm{Ti}_{5} \mathrm{Si}_{3}$ & 0.7429 & & 0.5139 & hexagonal & 0.37 & $11 \times 10^{-6}$ & & & \\
\hline TiSi & 0.6544 & 0.3638 & 0.4977 & $\begin{array}{c}\text { rhombo- } \\
\text { hedral }\end{array}$ & 0.2 & $10.4 \times 10^{-6}$ & 500 & 2200 & \\
\hline $\mathrm{TiSi}_{2}$ & 0.8253 & 0.4783 & 0.854 & $\begin{array}{l}\text { FC ortho- } \\
\text { rhombic }\end{array}$ & 0.52 & $\begin{array}{l}12.5 \times 10^{-6} \\
14.5 \times 10^{-6}\end{array}$ & 600 & 2060 & \\
\hline $\mathrm{Pd}_{2} \mathrm{Si}$ & 0.6497 & & 0.3437 & hexagonal & 0.2 & & $100-300$ & & \\
\hline $\mathrm{Pt}_{2} \mathrm{Si}$ & 0.3933 & & 0.5910 & tetragonal & -0.27 & & $200-500$ & & \\
\hline $\mathrm{Pt}_{3} \mathrm{Si}$ & 0.7716 & 0.7773 & 0.7776 & monoclinic & 0.42 & & 400 & & \\
\hline $\mathrm{TiSi}_{2}$ & 0.362 & 1.376 & 0.3605 & $\begin{array}{l}\text { BC ortho- } \\
\text { rhombic }\end{array}$ & -0.33 & & 600 & & \\
\hline $\mathrm{Au}_{2} \mathrm{Si}^{*}$ & 1.950 & & & Cubic & & & & & \\
\hline
\end{tabular}

BC - body centered; FC - face centered; FCC - face centered cubic. *Joint Committee for the Powder Diffraction Studees (JCPDS): Card Number 26-0724.

contacting with $\mathrm{Si}$, mismatch of lattice parameters $f=\left(a_{1}-a_{2}\right) / a_{2}$, where $a_{1}$ is the lattice parameter of film (in our case, silicide) and $a_{2}$ is that of $\mathrm{Si}$, exceeds 0.02 . According to [8], in this case, dislocations in the form of characteristic loops can be formed near the contactforming layer-Si interface.

Beside this, a number of other factors may serve as sources of dislocations. One can mention, for example, a developed microrelief that appears in the course of bombarding Si surface by metal atoms when depositing metal layers, as well as weakening of interatomic bonds near the metal film-Si interface that makes the Peierls barrier lower. Among other reasons, various stress risers may also play their role, e.g., such surface contaminations as thin nonuniform oxide layers and local microinclusions (it is very difficult to exclude them from the factual manufacturing process).

A high density of structural defects in a thin nearcontact region of silicon indicates the absence of recrystallization and structural ordering in the layers adjacent to the interface on the side of $\mathrm{Pd}_{2} \mathrm{Si}$ as well as $\mathrm{Si}$. These are just the defects via which in the course of metal deposition or annealing metal atoms penetrate into silicon, resulting in formation of metal shunts. 


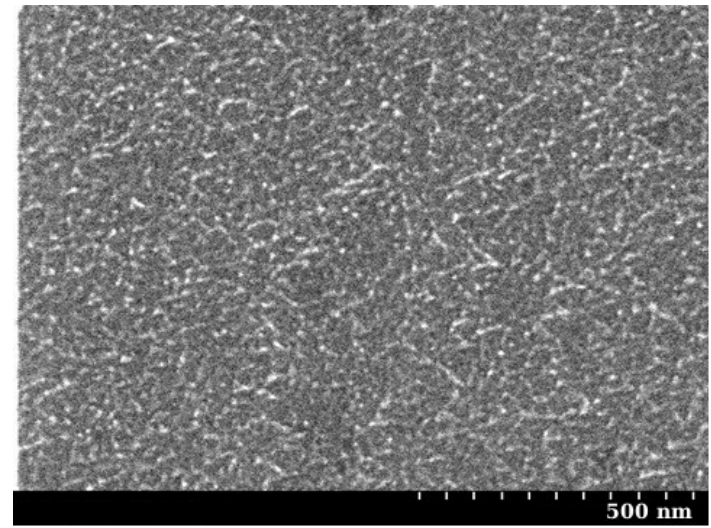

Fig. 14. SEM photograph of Si surface after removal of metallization and selective chemical etching with Wright etch (the specimen was annealed at $450^{\circ} \mathrm{C}$ for $10 \mathrm{~min}$ ).

\section{Electrical characteristics of palladium disilicide- based ohmic contact and discussion}

The parameters of ohmic contacts formed by palladium disilicide with $\mathrm{Ti}, \mathrm{Pt}$ and Pt-Ti barrier interlayers were almost the same for the initial and annealed specimens. In this case, annealing promoted reduction of contact resistivity $\rho_{c}$ in the 150 to $380 \mathrm{~K}$ temperature range practically by an order of magnitude. So, let us consider temperature dependence $\rho_{c}(T)$ that is typical for the contacts studied.

The $I-V$ curves of ohmic contacts obtained for TLM structures before and after annealing were linear within the whole range of temperature measurements. Both the calculated and measured $\rho_{c}(T)$ curves for the $\mathrm{Au}-\mathrm{Ti}-\mathrm{Pd}-n^{+}-\mathrm{Si}$ ohmic contact are presented in Fig. 15. The characteristic feature of dependence $\rho_{c}(T)$ is $\rho_{c}$ growing with temperature. This behavior is not described by the known mechanisms of current transfer in metal-semiconductor contacts. In [34], it was proposed to explain dependence $\rho_{c}(T)$ for similar ohmic contacts to $n-\mathrm{Si}$ by conduction via metal shunts associated with dislocations that appear in the nearcontact region of silicon. Checking that mechanism on ohmic contacts to lapped $\mathrm{Si}$ (with the initial dislocation density up to $10^{8} \mathrm{~cm}^{-2}$ ) demonstrated, in comparison with the experiment, adequacy of the proposed model $[27,28]$.

It should be noted that a high density of structural defects in the near-contact region of $\mathrm{Si}$ after annealing the $\mathrm{Al}-\mathrm{Si}$ ohmic contact at $510{ }^{\circ} \mathrm{C}$ for 15 min followed by removal of the metallization layer was observed in [35]. The density of structural defects (estimated from the etch pits) exceeded $10^{10} \mathrm{~cm}^{-2}$ (see Fig. 16 [35]). In that case, the $I-V$ curves of some test transistors with that metallization and defect near-contact region indicated the presence of short-circuits in the structure of transistor active areas.

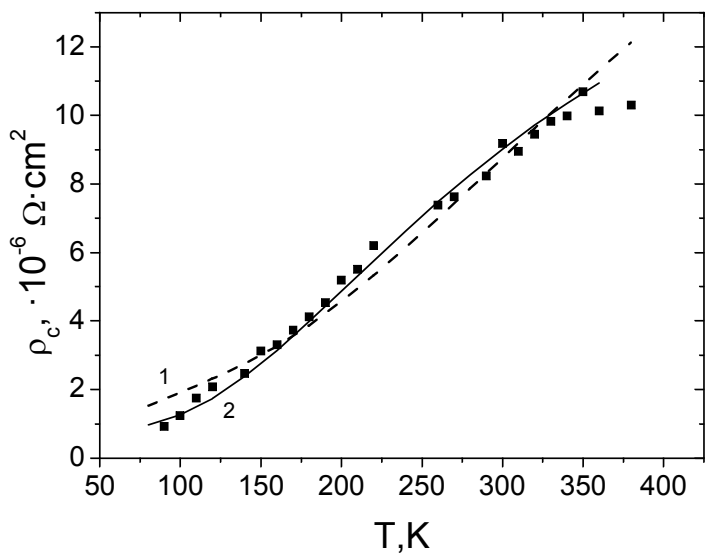

Fig. 15. Calculated (1) and measured (2) temperature dependences $\rho_{c}(T)$ for $\mathrm{Au}-\mathrm{Ti}-\mathrm{Pd}-n^{+}-\mathrm{Si}$ ohmic contact.

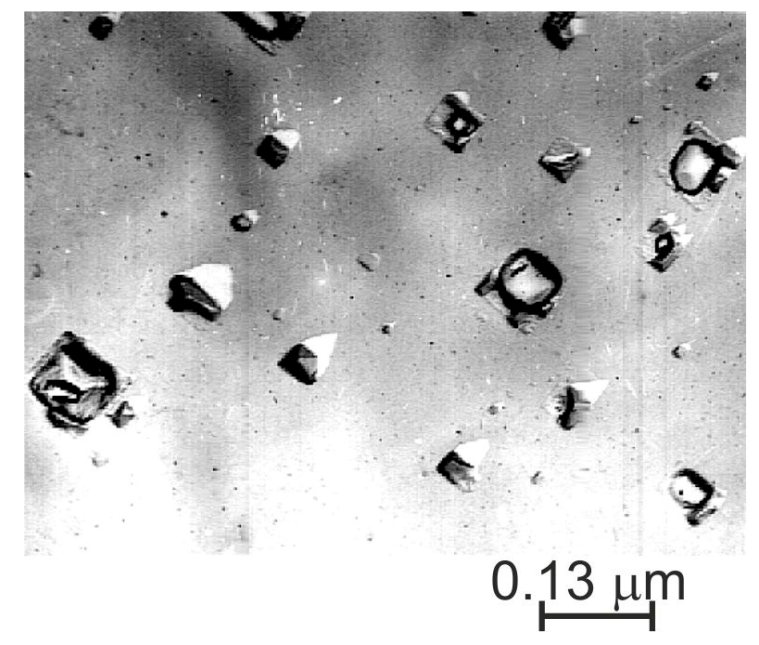

Fig. 16. Surface morphology of a silicon wafer (orientation $|100|)$ after removal of a pure aluminum film annealed at $510^{\circ} \mathrm{C}$ for $15 \mathrm{~min}$ [35].

The temperature dependence of $\rho_{c}$ for those contacts was not studied. We do not know a direct experiment to observe a rather high dislocation density in the near-contact region of Si appeared in the course of ohmic contact formation as well as investigation of its effect on the dependence $\rho_{c}(T)$. In our work, we made an attempt to compensate this gap.

Indeed, the above results on structural investigations of contact metallizations, contact-forming layer-silicon interface and near-contact region of Si after removal of metallization indicate one and the same. One can see that the $\mathrm{Pd}_{2} \mathrm{Si}-\mathrm{Si}$ interface is nonuniform in all three types of ohmic contacts based on the $\mathrm{Pd}_{2} \mathrm{Si}$ $\left(\mathrm{Au}-\mathrm{Ti}(\mathrm{Pt}, \mathrm{Pt}-\mathrm{Ti})-\mathrm{Pd}-n^{+}-\mathrm{Si}\right) \quad$ contact-forming layer, including the initial contact deposited onto a silicon substrate heated up to $350^{\circ} \mathrm{C}$ and annealed. After annealing at $450{ }^{\circ} \mathrm{C}$ for $10 \mathrm{~min}$, the near-contact region of Si has a high density of structural defects, first of all dislocations. 


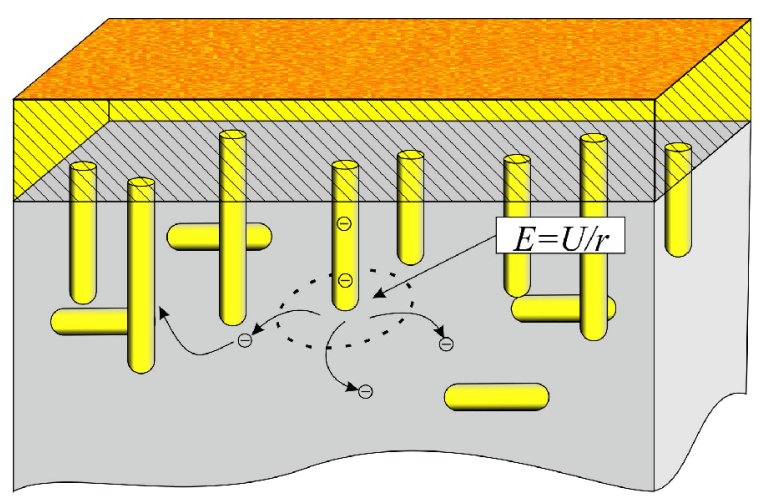

Fig. 17. Metal shunt end-semiconductor interface.

According to the model proposed in [34], an ohmic contact with a high density of dislocations in the nearcontact region of semiconductor is formed if:

- a high electric field appears at the semiconductor-end of metal shunt interface (see Fig. 17), $E=U / r, r$ is the shunt radius $\left(\sim 2 \cdot 10^{-8} \mathrm{~cm}\right)$. At $U=1 \mathrm{~V}, E \sim 5 \cdot 10^{7} \mathrm{~V} / \mathrm{cm}$;

- a potential well for electrons appears near the shunt end owing to high potential of mirror image forces $\Delta \varphi$, the sign of which is opposite to that of the Schottky potential;

- the flowing current is limited by diffusion supply of electrons, which is equivalent to the diffusion theory of current transfer in contact; according to this theory, $\rho_{c}(T) \sim 1 / \mu(T)$ and $\rho_{c}(T) \sim 1 / N_{D 1}$, where $\mu$ is the electron mobility, $N_{D 1}$ is the density of dislocations with associated metal shunts (the so-called conducting dislocations).

In this case,

$$
\rho_{C}(T)=\frac{k T}{q} \frac{1+\frac{q V_{T}}{4 k T \mu_{n}} e^{y_{C 0}} \int_{0}^{w} e^{-y(x)} d x}{\pi L_{D}^{2} N_{D 1} \frac{q V_{T}}{4} n_{w} e^{y_{C 0}}} .
$$

Here $n_{w}$ is the electron concentration in the semiconductor bulk, $y(x)$ is the dimensionless nonequilibrium potential at a point $x, q$ is the elementary charge, $V_{T}$ is the mean electron thermal velocity, $y_{C 0}=\frac{q \varphi_{C 0}}{k T}$ is the dimensionless equilibrium potential at the metal-semiconductor interface, $k$ is the Boltzmann constant, and $L_{\mathrm{D}}$ is the Debye shielding length.

One can see from the data shown in Fig. 15 that there is good agreement between the calculated and experimental $\rho_{c}(T)$ values obtained with allowance for temperature dependence of the electron mobility in $n$ - Si and conducting dislocation density $\sim 5 \cdot 10^{9} \mathrm{~cm}^{-2}$. This high $N_{D 1}$ value correlates with the experimentally observed (from etch pits) density of structural defects in the near-contact layer of $n^{+}-\mathrm{Si}$.
It should be noted that the observed density of structural defects may be somewhat higher than the calculated one, since not all the structural defects promote formation of metal shunts. It does not contradict to the known notions about types of structural defects in Si and their electrical activity [8].

\section{Conclusion}

Thus, our structural and morphological investigations of metallization in contacts for heavily doped $n$-Si and near-contact region of silicon showed that a high density of structural defects, in particular, dislocation loops $\left(\geq 10^{10} \mathrm{~cm}^{-2}\right)$ appears in the course of ohmic contact formation in a thin Si layer. The origin of these defects may be related to relaxation of stresses caused by mismatch of thermal expansion coefficients of silicide phases and $\mathrm{Si}$, and reduction of film volume of contactforming metal (in our case, $\mathrm{Pd}$ ) at $\mathrm{Pd}_{2} \mathrm{Si}$ formation.

Judging from the results of our metallographic analysis, formation of metal shunts is possible at annealing (contact firing) even before appearance of recrystallized layer. It is indicative of a high density of structural defects in a thin near-contact layer of silicon. However, the data obtained in our work do not give an answer about specific mechanism of appearance of a high density of structural defects in the Si near-contact layer. Elucidation of the nature of this phenomenon makes a separate problem; we plan to return to it later.

Our analysis of the temperature dependence $\rho_{c}(T)$ for contact metallization formed in the above way on the basis of the $\mathrm{Pd}_{2} \mathrm{Si}$ contact-forming layer showed that contact resistivity $\rho_{c}$ increases with temperature. It is related to the current flowing via metal shunts associated with dislocations. Good agreement was obtained between the calculated and experimental dependences $\rho_{c}(T)$ in ohmic contacts with a high dislocation density in the near-contact region of semiconductor. In this case (as follows from the model of formation of the prepared ohmic contact), the higher is the density of conducting dislocations in the near-contact layer of semiconductor, the lower is the contact resistivity.

\section{Acknowledgements}

This work was supported by the State Fund for Fundamental Researches SFFR-BRFFR-2013 (Project 54.1/012).

\section{References}

1. I.V. Grekhov, Yu.N. Seryozhkin, Avalanche Breakdown in $p$-n-Junction. Energiya, Leningrad, 1980 (in Russian).

2. F.E. Schubert, Light-Emitting Diodes. University Press, Cambridge, 2006.

3. M. Albrecht, H.P. Strunk, J.L. Weyher, I. Grzegory, S. Porowski, T. Wosinski, Carrier recombination at 
single dislocations in $\mathrm{GaN}$ measured by cathodoluminescence in a transmission electron microscope // J. Appl. Phys. 92(4), p. 2000-2005 (2002).

4. K.V. Ravi, Imperfections and Impurities in Semiconductor Silicon. John Willey \& Sons, New York, 1981.

5. V.A. Pilipenko, Rapid Heat Treatments in VLSI Manufacturing Technology, BGU Publishing Center, Minsk, 2004 (in Russian).

6. R. Quay, Gallium Nitride Electronics. SpringerVerlag, Berlin, 2008.

7. Technology of Gallium Nitride Crystal Growth, Eds. D. Ehrentraut, E. Meissner, M. Bockowski. SpringerVerlag, Berlin, 2010.

8. M.G. Mil'vidskii, V.B. Osvenskii, Structural Defects in Semiconductor Epitaxial Layers. Metallurgiya, Moscow, 1985 (in Russian).

9. A.R. Bhatti, R. Falster, G.R. Booker, TEM studies of the gettering of copper, palladium and nickel in Czochralski silicon by small oxide particles // Solid State Phenomena, 19-20, p. 51-56 (1991).

10. M.G. Mil'vidskii, A.M. Mil'vidskii, State of the art of semiconductor silicon technology, Part I // Materialovedenie, No.11, p. 15-26 (2006), in Russian.

11. M.G. Mil'vidskii, A.M. Mil'vidskii, State of the art of semiconductor silicon technology, Part II // Materialovedenie, No.12, p. 17-25 (2006), in Russian.

12. E.F. Venger, M. Grendel, V. Daniška, R.V. Konakova, I.V. Prokopenko, Yu.A. Tkhorik, L.S. Khazan, Structural Relaxation in Semiconductor Crystals and Device Structures. Phoenix, Kiev, 1994 (in Russian).

13. Ohmic Contacts to Semiconductors, Ed. B. Schwartz, Electrochem. Soc., New York, 1969.

14. D.A. Sechenov, V.I. Skorikov, V.V. Sokolenko, Production of ohmic contacts on silicon with high dislocation density // Obmen Opytom v Elektronnoi Promyshlennosti, No.5, p. 51-54 (1969), in Russian.

15. G.A. Zelikman, E.Z. Mazel', F.P. Press, S.V. Fronk, Semiconductor Silicon Diodes and Triodes, Manufacturing Technology. Energiya, Moscow, 1964 (in Russian).

16. Yu.L. Krasulin, Interaction between Metal and Semiconductor in a Solid Phase. Nauka, Moscow, 1971 (in Russian).

17. T.V. Blank, Yu.A. Gol'dberg, Mechanisms of current flow in metal-semiconductor ohmic contacts // Semiconductors, 41(11), p. 1263-1292 (2007).

18. T.V. Blank, Yu.A. Gol'dberg, O.V. Konstantinov, V.G. Nikitin, E.A. Posse, Peculiarities in the mechanism of current flow through an ohmic contact to gallium phosphide // Tech. Phys. Lett. 30(10), p. 806-809 (2004).

19. V.N. Bessolov, T.V. Blank, Yu.A. Gol'dberg, O.V. Konstantinov, E.A. Posse, Dependence of the mechanism of current flow in the $\mathrm{In}-n-\mathrm{GaN}$ alloyed ohmic contact on the majority carrier concentration // Semiconductors, 42(11), p. 13151317 (2008).

20. T.V. Blank, Yu.A. Gol'dberg, O.V. Konstantinov, V.G. Nikitin, E.A. Posse, The mechanism of current flow in an alloyed InGaN ohmic contact // Semiconductors, 40(10), p. 1173-1177 (2006).

21. Zhang Yeuzong, Feng Shiwei, Zhang Gongehang et al., High temperature characteristics of $\mathrm{Ti} / \mathrm{Al} / \mathrm{Ni} / \mathrm{Au}$ multilayer ohmic contact to $n-\mathrm{GaN} / /$ Chin. J. Semicond. 28(6), p. 984-988 (2007).

22. Zhang Yue-Zong, Feng Shi-Wei, Guo Chun-Sheng et al., High-temperature characteristics of $\mathrm{Ti} / \mathrm{Al} / \mathrm{Ni} / \mathrm{Au}$ ohmic contacts to $n-\mathrm{GaN} / /$ Chin. Phys. Lett. 25(11), p. 4083-4085 (2008).

23. T.V. Blank, Yu.A. Gol'dberg, E.A. Posse, Flow of the current along metallic shunts in ohmic contacts to wide-gap III-V semiconductors // Semiconductors, 43(9), p. 1164-1169 (2009).

24. A.E. Belyaev, N.S. Boltovets, R.V. Konakova, Ya.Ya. Kudryk, A.V. Sachenko, V.N. Sheremet, Temperature dependence of contact resistance of Au$\mathrm{Ti}-\mathrm{Pd}_{2} \mathrm{Si}-n^{+}-\mathrm{Si}$ ohmic contacts // Semiconductor Physics, Quantum Electronics and Optoelectronics, 13(4), p. 436-438 (2010).

25. A.V. Sachenko, A.E. Belyaev, A.V. Bobyl etal., Temperature dependence of the contact resistance of ohmic contacts to III-V compounds with a high dislocation density // Semiconductors, 46(3), p. 334-341 (2012).

26. A.V. Sachenko, A.E. Belyaev, N.S. Boltovets et al., Mechanism of contact resistance formation in ohmic contacts with high dislocation density // J. Appl. Phys. 111(8), 083701 (2012).

27. A.V. Sachenko, A.E. Belyaev, N.S. Boltovets et al., Features of temperature dependence of contact resistivity in ohmic contacts on lapped $n-\mathrm{Si} / / J$. Appl. Phys. 112(6), 063703 (2012).

28. A.V. Sachenko, A.E. Belyaev, N.S. Boltovets et al., The mechanism of contact-resistance formation on lapped $n-\mathrm{Si}$ surfaces // Semiconductors, 47(3), p. 449-454 (2013).

29. S.P. Murarka, Silicides for VLSI Applications. Academic Press, New York, 1983.

30. A.E. Gershinskii, A.V. Rzhanov, E.I. Cherepov, Thinfilm silicides in microelectronics // Mikroelektronika, 11(2), p. 83-94 (1982), in Russian.

31. Handbook of Physical Quantities, Eds. I.S. Grigoriev, E.Z. Meilikhov. CRC Press, 1996.

32. G.V. Samsonov, L.A. Dvorina, B.M. Rud', Silicides. Metallurgiya, Moscow, 1979 (in Russian).

33. D.K. Sarkar, S. Dhara, A. Gupta, K.G.M. Nair, S. Chaudhury, Structural instability of the ion beammixed $\mathrm{Au} / \mathrm{Si}(111)$ systems at elevated temperatures // Nuclear Instruments and Methods in Physics Research, Section B: Beam Interactions with Materials and Atoms 168(1), p. 21-28 (2000).

34. A.V. Sachenko, Formation mechanisms of contact resistance of metal-semiconductor ohmic contacts, in: Physical Diagnostic Methods in Micro- and Nanoelectronics, Eds. A.E. Belyaev, R.V. Konakova, p. 281-346. ISMA, Kharkov, 2011 (in Russian).

35. L.D. Buyko, V.P. Lesnikova, V.A. Pilipenko, V.V. Rozhkov, The features of interaction of $\mathrm{Al}-\mathrm{Si}$ system under thermal and pulsed optical treatments // Elektronnaya Tekhnika, Ser. 6 Materialy, No.2, p. 1621 (1984), in Russian. 